\title{
Challenge of post-COVID era: management of cardiovascular complications in asymptomatic carriers of SARS-CoV-2
}

\author{
Shreyasi Gupta ${ }^{1}$ (D) Arkadeep Mitra $^{2}$ (D) \\ Accepted: 5 January 2021 / Published online: 11 January 2021 \\ (c) The Author(s), under exclusive licence to Springer Science+Business Media, LLC part of Springer Nature 2021
}

\begin{abstract}
Severe Acute Respiratory Syndrome Coronavirus-2 (SARS-CoV-2), a highly pathogenic member of family coronaviridae, has caused an exponentially growing global pandemic termed as the coronavirus disease 2019 (COVID-19) with more than 12 million cases worldwide till date. This deadly disease has average fatality rate of $6.5 \%$ and even higher among elderly patients and patients with comorbidities. SARS-CoV-2 uses angiotensin-converting enzyme 2 (ACE-2) as the entry receptor into host cell. ACE-2, a type-I transmembrane metallocarboxypeptidase, is a critical regulator of the renin-angiotensin system. The entry of SARS-CoV-2 within host cells results in a reduced availability of ACE-2 on the host cell surface followed by significant downregulation of ACE-2 gene expression. As ACE-2 is a well-known cardio-protective molecule, its downregulation could result in severe cardiac disorders. This review deals with a challenging aspect of SARS-CoV-2 infected patients who are asymptomatic or have mild syndromes similar to influenza infections. These patients are proving to be the Achilles' heel to combat COVID-19 mainly in developing countries of South Asia, where the average number of tests conducted per million individuals is considerably low. Consequently, there is high possibility that individuals with negligible respiratory trouble will not be tested for SARS-CoV-2. Hence, a huge percentage of the population have the risk of developing cardiovascular disorders as a bystander effect of viral infection apart from being potential reservoir of disease transmission. Based on available demographic as well as molecular data, this review predicts a huge spike in cardiovascular disorders among this undetected reservoir in post COVID-19 era.
\end{abstract}

Keywords SARS-CoV-2 $\cdot$ COVID-19 $\cdot$ ACE-2 $\cdot$ Asymptomatic patients $\cdot$ Cardiovascular disorders

\section{Introduction}

In the latter half of December, 2019, outbreak of a deadly disease caused by Severe Acute Respiratory Syndrome Coronavirus-2 (SARS-CoV-2) [1] was reported in the city of Wuhan in the People's Republic of China, which has subsequently affected more than 200 countries worldwide till date. The disease was referred as the corona virus disease 2019 (COVID-19) [2]. Symptomatic patients of this disease exhibit fever, dry cough, and shortness of breath [3]. Sometimes infection causes a sudden cytokine storm leading to acute respiratory distress syndrome (ARDS) [4].

Arkadeep Mitra

arkadeep.mitra1986@gmail.com

1 Department of Zoology, Triveni Devi Bhalotia College, Paschim Bardhaman, Raniganj 713 347, India

2 Department of Zoology, City College, 102/1, Raja Rammohan Sarani, Kolkata 700 009, India
Although SARS-CoV-2 has a predilection for the lungs and in all symptomatic patients respiratory complications have been strongly associated with mortality, cardiac involvement is also proving to be a critical factor in COVID-19 patients [5]. A study conducted on 72,314 patients by Chinese Center for Disease Control and Prevention revealed that the fatality rate for underlying cardiovascular disease (10.5\%) is even larger than for patients with chronic respiratory disease (6.3\%) [6]. This finding is really contrasting with the H1N1 influenza outbreak in 2009 [7]. A meta-analysis of six published studies from China, performed with a sample size of 1527 COVID-19 patients, revealed prevalence of cardio-cerebrovascular disease and hypertension in $16.4 \%$ and $17.1 \%$, respectively, of the sample pool. The overall case fatality rate (CFR) was found to be $2.3 \%$ in the entire cohort but significantly higher ( $10.5 \%$ and $6 \%$ respectively) in patients with CVD and hypertension [8].

Interestingly, cardiovascular disorders in COVID-19 may also arise from direct effects of the pathogen itself. 
SARS-CoV-2 may cause myocarditis that induces acute coronary events and strokes similar to many other viral infections [9]. However, a more specific and critical aspect of SARS-CoV-2 infection is its initial entry receptorangiotensin-converting enzyme 2 (ACE-2), a major regulator of the renin-angiotensin system (RAS). Along with hijacking host cell-surface ACE-2, upon entry, SARS-CoV-2 also downregulates its expression [10] which leads to diminished protective effects on cardiovascular system [11].

This poses a serious threat for the huge pool of SARSCoV-2 infected individuals in developing countries of South Asia. These individuals are either asymptomatic or have very mild flu-like syndromes and hence are highly probable candidates for remaining untested. This article aims to provide a comprehensive review on a possible spike in cardiovascular disorders in these asymptomatic individuals to assist physicians and researchers in their efforts to efficiently address this associated burden of the pandemic.

\section{Demography of SARS-CoV-2 infection in South Asian countries}

South Asia is the southern region of the Asian continent, which comprises the sub-Himalayan countries and a few adjoining countries to the west and east. According to modern definitions, the current territories of Afghanistan, Bangladesh, Bhutan, Maldives, Nepal, India, Pakistan, and Sri Lanka form South Asia. These eight countries are members of The South Asian Association for Regional Cooperation (SAARC)-an economic cooperation organization established in 1985 [12].

Demographic data according to worldometers.info (Dover, Delaware, U.S.A) as on 27 October 2020 [13], revealed that the number of COVID-19 positive cases/1 million population is quite high in SAARC countries barring Sri Lanka and Bhutan (Table 1). On the contrary, the number of tests conducted/1 million population is quite low in Pakistan, Bangladesh, and Afghanistan (Table 1). Republic of Maldives has reported highest number of positive cases/1 million population (Table 1). However, they have also conducted highest number of tests /1 million population among all SAARC countries.

\section{Biology of SARS-CoV-2}

\section{Taxonomy and nomenclature}

Corona viruses (CoVs) are the largest group of viruses belonging to order Nidovirales. There are four families under order Nidovirales viz., Coronaviridae, Arteriviridae, Mesoniviridae, and Roniviridae. Family Coronaviridae comprises of two subfamilies-Othocoronavirinae and Torovirinae. Subfamily Coronavirinae is subdivided into four genera $-\alpha, \beta, \gamma$, and $\delta$ corona viruses [14]. Human corona viruses were first identified in the mid-1960s. So far, seven corona viruses have been identified that can infect human-229E ( $\alpha$-corona virus), NL63 ( $\alpha$-corona virus), OC43 ( $\beta$-corona virus), HKU1 ( $\beta$-corona virus), Middle East Respiratory Syndrome (MERS)-CoV ( $\beta$-corona virus), SARS-CoV ( $\beta$-corona virus), and the latest SARS-CoV-2 ( $\beta$-corona virus) [14]. Corona virus virions that are spherical with club-shaped spike projections emanating from the surface give them the appearance of a solar corona, prompting the name, corona viruses [15].
Table 1 Demographic data of COVID-19 from the eight member countries of SAARC

\begin{tabular}{lllll}
\hline S1 no & Countries & Population & $\begin{array}{l}\text { Cases/1 million } \\
\text { population }\end{array}$ & $\begin{array}{l}\text { Tests/1 mil- } \\
\text { lion popula- } \\
\text { tion }\end{array}$ \\
\hline 1 & India & $1,384,345,261$ & 5740 & 75,430 \\
2 & Pakistan & $222,246,653$ & 1482 & 19,427 \\
3 & Bangladesh & $165,214,241$ & 2423 & 13,748 \\
4 & Afghanistan & $39,203,946$ & 1044 & 3072 \\
5 & Nepal & $29,302,615$ & 5454 & 47,715 \\
6 & Sri Lanka & $21,442,186$ & 392 & 21,026 \\
7 & Bhutan & 774,322 & 442 & 215,728 \\
8 & Republic of Maldives & 543,558 & 21,216 & 277,326 \\
\hline
\end{tabular}

Source of data: Ministry of Health and Family Welfare, Government of India (https://www.mohfw.gov.in/); Ministry of National Health Services Regulations and Coordination, Government of Pakistan (https://covid. gov.pk/); Ministry of Health and Family Welfare, Bangladesh (http://corona.gov.bd/); Ministry of Public Health, Afghanistan (https://moph.gov.af/); Ministry of Health, Republic of Maldives (https://covid19.health. gov.mv/dashboard/); Health Promotion Bureau, Sri Lanka (https://www.hpb.health.gov.lk/en); Ministry of Health and Population, Nepal (https://covid19.mohp.gov.np/\#/); and Ministry of Health, Royal Government of Bhutan (http://www.moh.gov.bt/) [Data updated as on 27 October 2020] 


\section{Basic genome structure}

Similar to all viruses belonging to order Nidovirales, SARSCoV-2 are also enveloped, non-segmented positive-sense RNA viruses having very large genome of about $30 \mathrm{~kb}$. The genome contains a very large replicase gene that occupies about $20 \mathrm{~kb}$, whereas the structural and accessory genes make up about $10 \mathrm{~kb}$ of the viral genome. The SARSCoV-2 genome contains a $5^{\prime}$ cap structure followed by a leader sequence and untranslated region (UTR) along with a $3^{\prime}$ poly (A) tail, similar to an mRNA for translation of the replicase gene [16]. There are four main structural protein coding genes in Corona virus genome-spike (S), membrane $(\mathrm{M})$, envelope (E), and nucleocapsid (N). Among them, the $\mathrm{S}$ gene codes for a $150-\mathrm{kDa} S$ protein. Homotrimers of spike protein are critical for attachment to the host receptor [17].

\section{Entry to host cell and life cycle}

The initial attachment of the SARS-CoV-2 virion to the host cell is initiated by interactions between the $S$ protein and its receptor-ACE-2 [18]. After receptor binding, the spike protein undergoes acid-dependent proteolytic cleavage, followed by fusion of the viral and host cellular membranes and ultimately release of the viral genome into host cytoplasm [19]. After release, the next step in its life-cycle is translation of the replicase gene from the virion genomic RNA. The replicase gene codes for nonstructural proteins (nsps), many of which assemble into the replicase-transcriptase complex (RTC) that facilitate RNA replication and transcription. Viral RNA synthesis produces genomic RNAs as well as sub-genomic RNAs that serve as mRNAs for the structural and accessory genes [20]. After successful replication and synthesis of sub-genomic RNA, the structural proteins, S, E, and M are translated and inserted into host endoplasmic reticulum. Then they move along the endoplasmic reticulum-Golgi-intermediate vesicular compartment (ERGIC) secretory pathway. There, viral genomes encapsidated by the $\mathrm{N}$ protein bud into membranes of the ERGIC with viral structural proteins, thus forming mature virions [21]. Next, S protein is incorporated into virions. Finally, the $\mathrm{M}$ protein promotes the completion of virion assembly with assistance from E protein [22]. On completion of assembly, virions are transported to the cell surface in vesicles and finally released by exocytosis.

\section{Pathogenecity}

Prior to the SARS-CoV (2002-2003), MERS-CoV (2012), and SARS-CoV-2 (2019-2020) outbreak, corona viruses were reported to cause mild, respiratory infections in humans. A study using autopsy samples of patients who died of SARS$\mathrm{CoV}$ revealed predominant presence of the virus in lung, trachea, and bronchus. Interestingly, SARS-CoV was also detected in many other organs and tissues, viz., stomach, small intestine, liver, distal convoluted renal tubule, and kidney [23]. This study indicated that along with the respiratory system, other organs may also be targets of SARS-CoV and cause detrimental effect (Fig. 1).

Clinical symptoms of SARS-CoV-2 infection vary a greatly from patient to patient. The virus invariably first affects the respiratory epithelial cells and alveolar cells, followed by the digestive system. Many SARS-CoV-2 cases express diarrhoea as the initial symptom [24]. Liver dysfunction is another complication that has been reported during COVID-19 [25]. ACE2 expression in colon cells is positively correlated with the regulation of cellular immunity. This might also be destabilized due to SARS-CoV-2 infection [26].

Cardiovascular complications are being documented in increasing number of patients with COVID-19. A study on 41 individuals first diagnosed with SARS-CoV-2 infection revealed 5 patients to have viral myocarditis with elevated hscTnl and mean systolic blood pressure. Common symptoms of cardiovascular disease such as palpitations, chest tightness, and short of breath were also reported in these patients [2]. Another study with 84 patients of SARS-CoV-2 infection revealed significant elevation of creatine kinase and creatine kinase MB which is a sign of acute myocardial injury [26]. Huang et al. also observed Th1/Th2 imbalance in COVID-19 patients that triggers release of a large amount of cytokines resulting in myocardial injury [2].

Fan et al. has reported that ACE2 is highly expressed in renal tubular cells, mesenchymal cells, and testicular and vas deferens cells. Entry of SARS-CoV-2 has been confirmed in these cells, and detrimental effects of the virus on kidney and testes have also been [27]. Recent reports have also shown the presence of viral nucleic acid in patient's cerebrospinal fluid and brain tissue. Due to unique anatomical structure of the olfactory tract, it serves as an important channel for virus transmission from nasal epithelium to central nervous system (CNS) [28]. Even in some cases, symptoms of intracranial infection such as headache, epilepsy, and confusion have preceded the symptoms of pulmonary infection like cough, fever, and dyspnoea. Besides this, swelling of brain cells, interstitial oedema, obstruction of cerebral blood flow, etc., have also been observed as secondary effect of respiratory impairment [29]. However, more detailed study is required to assess the effect of SARS-CoV-2 on urinogenital system as well as CNS.

\section{ACE2- the gateway for SARS-CoV-2}

\section{Domain structure of ACE2}

ACE2 gene, located on chromosome $\mathrm{X}$, is a very close homologue of the ACE gene located chromosome 17 in 


\section{Respiratory System}

\section{Cardiovascular System}

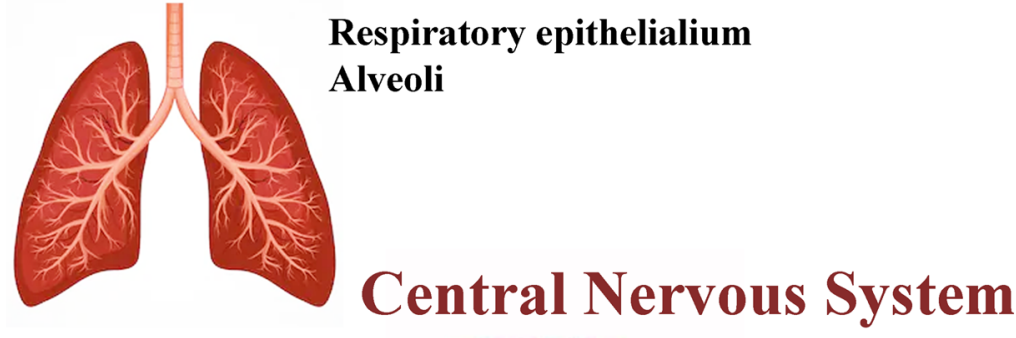

Myocardium, Endothelium
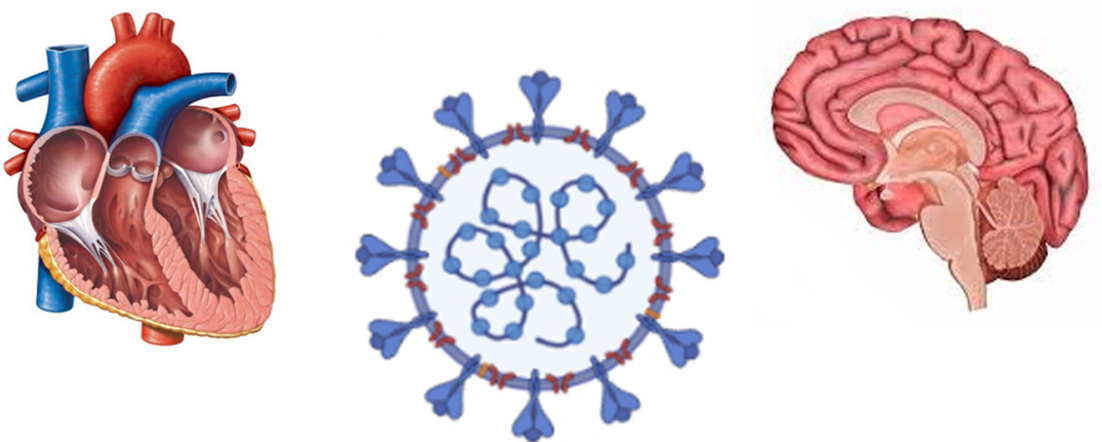

Cerebrum

Glial Cells

Pituitary

\section{Urinogenital System}

Kidney,

Distal convoluted renal tubule,

Mesenchymal cells,

Testicular and vas deferens cells
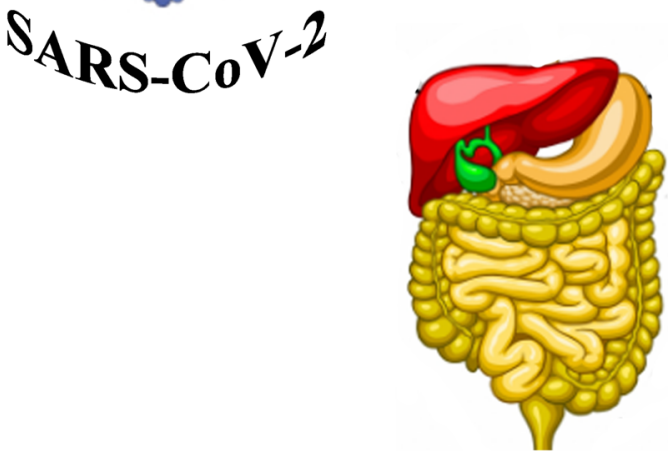

Digestive System

Oesophagus

Stomach,

Small intestine,

Liver

Colon

Rectum

Fig. 1 Schematic diagram showing human physiological systems affected by SARS-CoV-2 and the major targets of the virus as reported in literature

human. Sequence comparison has revealed that similar to ACE, ACE2 also codes for a type I integral-membrane protein (N-terminus outside, $\mathrm{C}$-terminus intracellular) and ectoenzyme [30]. ACE2 protein consists of three domains, viz., an N-terminal ectodomain (residues 1-740), a transmembrane region (residues 741-762), and a short C-terminal cytoplasmic tail (residues 763-805) [31] (Fig. 2a, b). The ectodomain contains a single active site which contains a characteristic zinc-binding motif
(HEMGH) [32] as shown in Fig. 4b. So far, 3 sites has been identified in the ectodomain as putative binding sites for SARS-CoV spike glycoprotein-residues 30-41, residues 82-84, and residues 353-357 [33]. Two cleavage sites were identified at residues $652-659$, for the enzyme a disintegrin and metallopeptidase domain 17 (ADAM 17), and residues 697-716 for type II transmembrane serine protease TMPRSS2 [34]. These sites play critical role in ACE2 signalling to be discussed later in this article. 


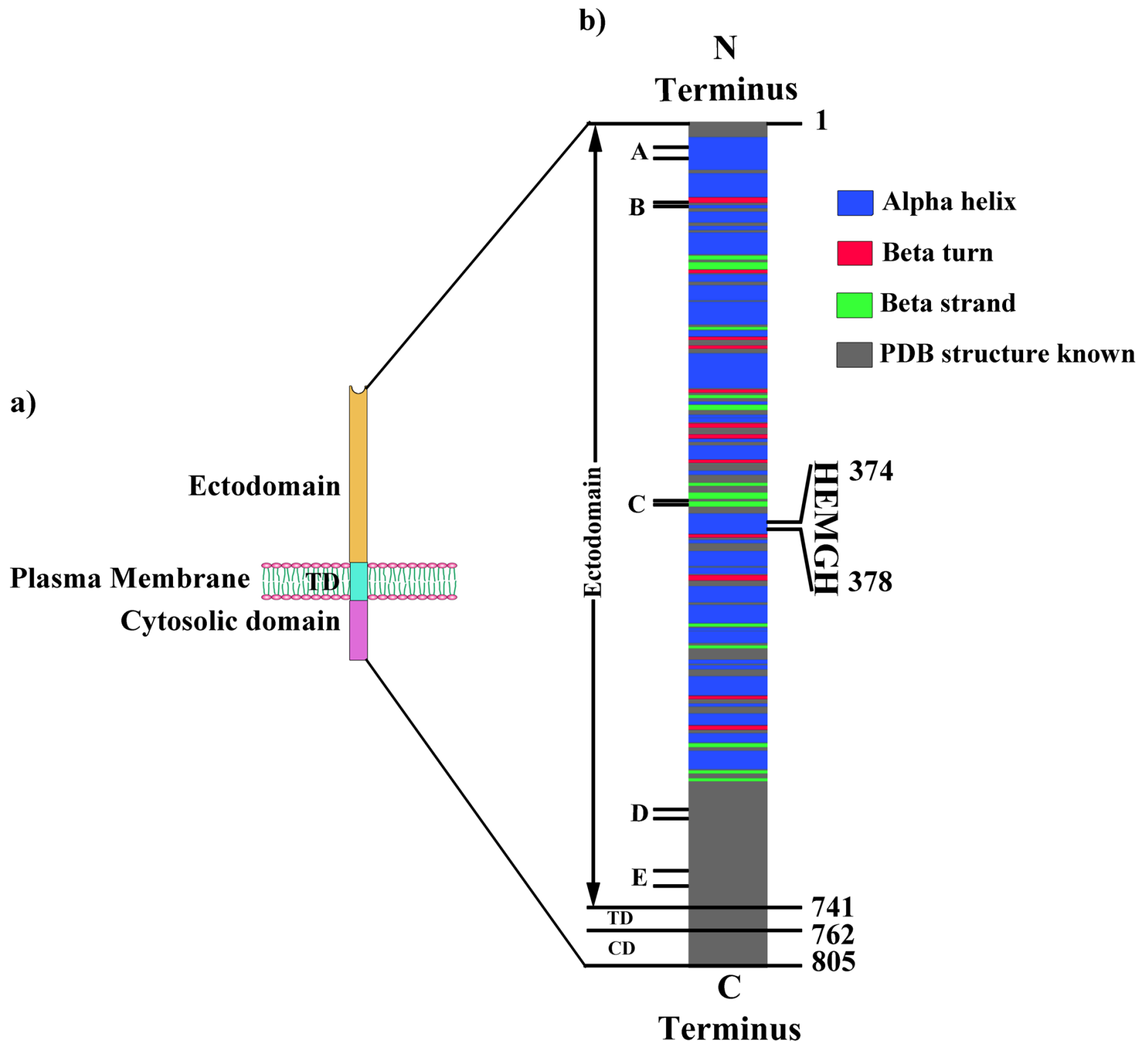

Fig. 2 a Schematic diagram and $\mathbf{b}$ detailed secondary structure of ACE2 reconstructed from UniProt database [70]. TD transmembrane domain, CD cytosolic domain. Sites A (residues 30-41), B (residues 82-84), and C (residues 353-357) represent putative binding sites

\section{Tissue distribution of ACE2}

ACE2 was originally identified to be expressed in tissues such as testis, heart, and kidney [35], where they were found to be localized on the apical membrane of polarized cells. Later ACE2 has been mapped in liver, intestine, lung [36], and more recently brain [37]. Li et al. also reported that tissue distribution pattern and expression levels of ACE2 have no significant difference between males and females, between younger and older persons, or between Asian and non-Asian races [38]. for SARS-CoV spike glycoprotein. Sites D (residues 652-659) and E (residues 697-716) serve as respective cleavage sites for ADAM 17 and TMPRSS2. The single active site of ACE2 contains a characteristic zinc-binding motif (HEMGH) at residues 374-378

\section{Renin-angiotensin system and ACE2}

The renin-angiotensin system (RAS) encompasses a complex and wide network of enzymes, peptides, and receptors (Fig. 3) that regulates blood pressure, fluid and electrolyte balance, and systemic vascular resistance [39]. Reduction of renal blood flow stimulates the conversion of prorenin to rennin by juxtaglomerular cells in the kidneys. Plasma renin then converts angiotensinogen (1-255), released by the liver, to the decapeptide angiotensin I (Ang I (1-10)). Ang I is then converted to angiotensin 
Fig. 3 Schematic diagram showing involvement of ACE2 in the Renin-Angiotensin pathway (Ang I (1-10): Angiotensin I; Ang II (1-8): Angiotensin II; AT1R: Angiotensin II receptor type 1; AT2R: Angiotensin II receptor type 2)

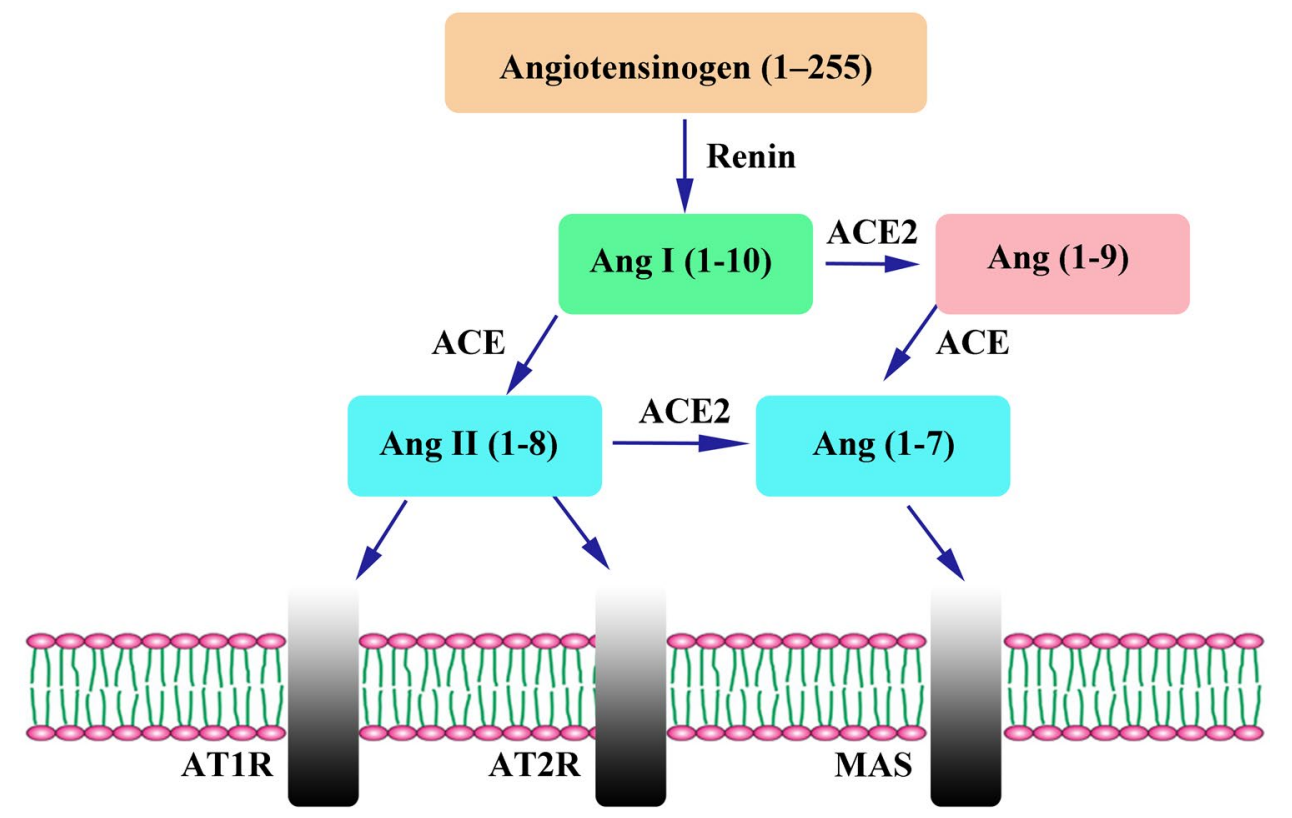

II (Ang II or Ang-(1-8)) by the angiotensin-converting enzyme (ACE). Ang II is a vasoconstrictive peptide that causes an increase in blood pressure. It also stimulates adrenal cortex to secrete aldosterone that causes the renal tubules to increase the reabsorption of sodium and in turn reabsorption of water into the blood. Simultaneously, it induces the excretion of potassiumin order to maintain electrolyte balance. This ultimately increases the volume of extracellular fluid in the body resulting in increased blood pressure [40].

After the initial discovery of ACE2 in 200035 , researchers have shown over the last 20 years that it plays a pivotal role in the RAS. However, despite having high structural homology to ACE, ACE2 cannot convert Ang I to Ang II. This is due to a major difference in enzyme function-ACE2 is a carboxy-peptidase that removes a single amino acid from the C-terminus of substrates, whereas ACE is a carboxy-dipeptidase that removes a C-terminal dipeptide [41]. As a consequence, ACE2 hydrolyses Ang I and converts it to Ang-(1-9) rather than Ang II. However, studies revealed that ACE2 has almost 400-fold higher catalytic efficiency for hydrolysis of Ang II compared with Ang I. ACE2 hydrolyses Ang II to produce the main product of its catalytic activity-Ang-(1-7), a vasodilatory peptide [42]. Santos et al. have identified the G-protein-coupled receptor Mas, as the receptor for Ang-(1-7) [43]. The downstream physiological responses of activation of Mas receptor include vasodilation (sensitization of the baroreflex), vascular protection, antifibrosis and reduction in pro-inflammatory cytokines-all of which are counteractive to the actions of AT1 receptor, the target of Ang II [32].

\section{Shedding of ACE2 ectodomain}

A very interesting phenomenon regarding ACE2 is its proteolytic cleavage from the cell surface by a cellular process known as ectodomain shedding. It results in release of the enzymatically active ectodomain into interstitial space and circulation. This process is mediated by protease(s) referred to as sheddase. Two such proteases-ADAM 17 and TMPRSS2 - have been identified which cleave ACE2 at different sites as mentioned earlier in this article. Hence, there are two different forms of shedded ACE2 ectodomain and both forms retain enzymatic activity [44]. Several factors viz., Ang II, tumour necrosis factor, interleukin $1 \beta$, and disintegrin metalloproteases, have been reported to induce ACE2 shedding in mice and humans [45, 46]. Patel et al. predicted that the increase in circulating ACE2 due to shedding of ACE2 by ADAM-17 from its normal tissue membrane location occurs due to a feedback loop involving Ang II [46]. Heurich et al. has shown that cleavage by TMPRSS2 resulted in an augmented entry of the SARSCoV S protein into host cells in vitro 34 .

\section{Entry of SARS-CoV-2 using ACE2}

It has already been mentioned earlier that ACE2 acts as the major entry receptor for both SARS-CoV and SARS-CoV-2. Priming of SARS-CoV-2 S proteins by host cell proteases is essential for entry of the virus into host cells. TMPRSS2, which is employed by SARS-CoV-2, plays a critical role in $\mathrm{S}$ protein priming. It cleaves $S$ protein at the $S 1 / \mathrm{S} 2$ and the $S 2^{\prime}$ sites [47]. Following priming, the spike protein interacts with the ectodomain of ACE2, which induces clathrin-dependent 
endocytosis of the virus-receptor complex. Clathrincoated pits are formed by interactions between the ACE2SARS-CoV-2 complex and the AP2/clathrin complex via a supposed co-receptor in a non-lipid-raft portion of the host cell membrane (Fig. 4). The ACE2/virus complex is then translocated to endosomes, where the virus is uncoated by endosomal acid protease like cathepsin L [48].

\section{Downregulation of ACE2 by SARS-CoV-2}

It has already been discussed in this article that SARSCoV-2 hijacks ACE2 as its entry receptor. Haga et al. have shown that binding of recombinant and virion-associated SARS-S protein to ACE2 leads to its shedding in an ADAM17/tumour necrosis factor alpha (TNF- $\alpha$ )-converting enzyme (TACE)-dependent manner [49]. This finding was reinforced by study of Glowacka et al., which revealed that virus-like particles (VLPs) bearing SARS-S protein triggered ACE2 shedding in Vero E6 cells in vitro [50]. This study also showed that ACE2 shedding contributes to ACE2 downregulation, confirming a previous observation by Kuba et al. [51]. Apart from this, SARS-CoV-2 infection results in a rapid increase in the levels of cytokines IL-2 and IL-7, which in turn repress the expression of ACE2 in mouse T cells and human tissues [52]. Very recently, Fadason et al. reported several putative regulatory elements within ACE2 gene. The study revealed that virus-induced reduction of ACE2 gene expression occurs due to chromatin remodelling which also alters the activity of gene regulatory regions.
This in turn alters expression pattern of several host factors and promotes an intra-cellular environment suitable for viral replication [53]. However, more in-depth analysis regarding the regulation of ACE2 gene expression by SARS-CoV-2 is required in order to decipher the underlying molecular mechanisms.

\section{ACE2 and cardiovascular system}

Association between RAS and cardiovascular system is well known. Since discovery of the vasoconstrictive octapeptide Ang II-it has been well established as a major regulator of cardiovascular physiology [30].After a span of more than 30 years, the heptapeptide Ang-(1-7) was identified which is counter-regulatory in comparison to the actions of Ang II [54]. However, it was ACE2 whose discovery established a novel enzymatic pathway and legitimized the counterregulatory role of Ang-(1-7) [35]. Ang II is the principal substrate for ACE2; several peptides have been identified so far as substrates for this enzyme, viz., apelin-13, neurotensin, kinestensin, dynorphin, and bradykinin (Bk) fragments, [des-Arg9]-Bk and [Lys-des-Arg9]-Bk [42]. All these peptides have been reported to exhibit vasoactive potential in the cardiovascular system. They have important implications in blood pressure control, cardiac function, and vascular reactivity. In brief, studies over the last two decades have firmly established that primary action of ACE2 is to tip
Fig. 4 Schematic diagram showing the pathway for entry of SARS-CoV2 to host cell. (1) Priming of SARS-CoV-2 spike (S) proteins by host cell protease (TMPRSS2). (2) Interaction of the $S$ protein with the ectodomain of ACE2 following priming. (3) Formation of clathrin-coated pits by interactions between the ACE2-SARS-CoV-2 complex and the AP2/clathrin complex via a supposed co-receptor in a non-lipid-raft portion of the host cell membrane

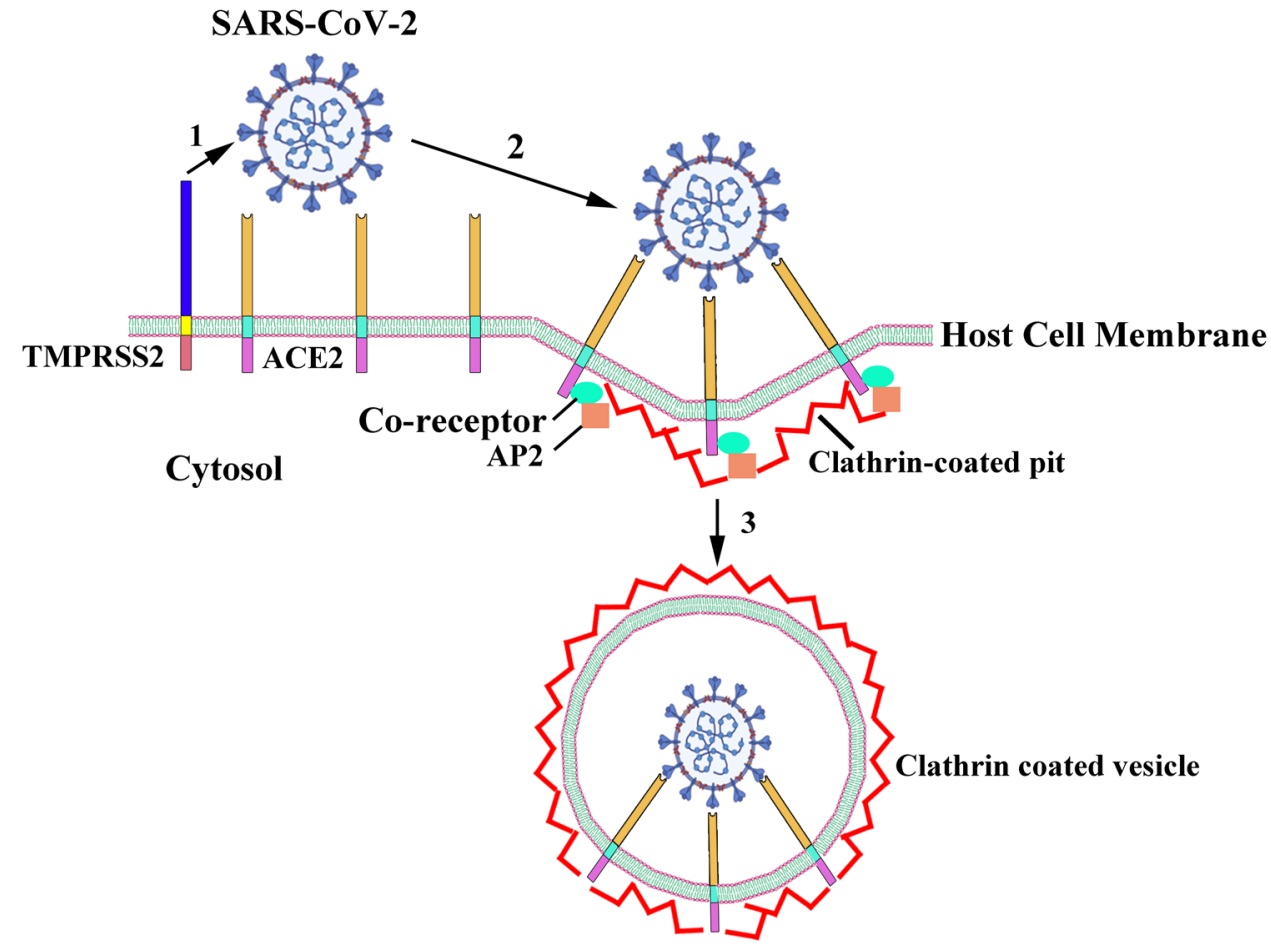


the scales from vasoconstrictive to vasodilatory peptides to maintain cardiovascular homeostatsis [54].

The importance of ACE2 in the cardiovascular system as a pivotal molecule has been affirmed using deletion strains as well as over-expression models. Crackower et al. performed targeted disruption of ACE2 gene in mice that resulted in severe cardiac contractility defect with increased angiotensin II levels and upregulation of hypoxia-induced genes within heart cells [55]. Another study using an Ang II-dependent hypertension model revealed significant elevation of blood pressures in the ACE2-null mice in comparison with wild type [56]. Yamamoto et al. also demonstrated that mice lacking ACE2 [ACE2(-/y)] showed reduced cardiac contractility along with markedly increased cardiac Ang II concentration and activity of mitogen-activated protein (MAP) kinases in response to transverse aortic constriction (TAC). Activation of the MAP kinases in response to Ang II was also much greater in cardiomyocytes isolated from ACE2(-/y) mice in comparison with those isolated from WT mice [57]. On the other hand, transgenic mice overexpressing ACE2 in cardiomyocytes exhibited spontaneous episodes of ventricular tachycardia and fibrillation [58]. All these studies indicate that optimum expression of ACE2 is imperative for maintaining cardiac function.

\section{Cardiovascular complications in asymptomatic individuals infected by SARS-CoV-2}

Asymptomatic persons account for approximately 40 to $45 \%$ of SARS-CoV-2 infections. Not only can they transmit the virus to others for an extended period but also have chances of developing several subclinical symptoms. Several reports are cropping up which indicate that the absence of COVID-19 symptoms in persons infected with SARS-CoV-2 might not necessarily imply complete absence of harm [59]. Yu et al. had previously summarized the cardiovascular complications associated with SARS$\mathrm{CoV}$ in a group of 121 patients [60]. About $50.4 \%$ of the patients experienced significant hypotension. However, all of them were asymptomatic except in one patient. Significant sinus bradycardia was seen in $14.9 \%$ patients, all of whom were asymptomatic. Other complications included cardiac arrhythmia and cardiomegaly in patients who were again mostly asymptomatic. A study conducted on non-critically ill patients in Dongxihu Fangcang Hospital, China, also revealed cardiovascular diseases in $1.5 \%$ of patients and aggravated in 5\% patients during follow-up [61]. Another study involving 100 German patients who had recently recovered from COVID-19 revealed abnormalities in the hearts of $78 \%$ of the cohort. Strikingly, most patients involved in this study had not required hospitalization for treatment of COVID-19 [62].

Another cause of concern is the drugs that are currently being used to treat COVID-19. Especially, drugs such as hydroxychloroquine (HCQ) and azithromycin have been reported to prolong QT interval and have a proarrhythmic propensity [63]. A study involving asymptomatic or mildly symptomatic children with SARS-CoV-2 infection has revealed impaired ventricular repolarization and increased risk of developing ventricular arrhythmia [63].

Pre-existing cardiovascular disorders and their associated risk factors such as hypertension, obesity, and diabetes mellitus have been reported to pose significant threat during SARS-CoV-2 infection. In most patients requiring intensive care, one or more of the aforementioned preexisting comorbities were reported subsequently [64, 65]. Interestingly, many of those patients were leading normal life prior to SARS-CoV-2 infection and their cardiovascular impairment aggravated due to COVID-19. Pre-existing inflammation within the cardiac environment could also be deadly as SARS-CoV-2 dramatically increases pro-inflammatory cytokines and promotes systemic inflammation. This may lead to an increased risk of coronary plaque rupture, Furthermore, pro-coagulant effects of systemic inflammation may increase the risk of stent thrombosis [66]. The clinical effects of pneumonia lead to an increased risk of cardiovascular disease even up to 10-year follow-up [67], and it is highly possible that patients infected by SARS-CoV-2 will experience similar adverse outcomes.

\section{Management of cardiovascular complication during and post-COVID era}

CVDs include complex and diverse pathophysiological conditions and hence COVID-19 patients need to be triaged based on the specific complication. Hypertension is a major comorbity reported in COVID-19 patients. Several studies have shown that treatment with angiotensin converting enzyme inhibitors/angiotensin II receptor blockers (ACE-i/ARB) should be continued for hypertension management in these patients [68]. Acute coronary syndrome (ACS) is a condition that is generally diagnosed on the basis of previous history, electrocardiogram (ECG), and troponin levels. However, classic symptoms of ACS may be overshadowed during COVID-19, potentially leading to under-diagnosis. Hence, even in the absence of any ischemic aetiology, ECG and serial measurement of tropnin levels must be performed [68]. Myocardial injury is another common factor in patients with moderate to severe SARS-CoV-2 infection. Similar to ACS, this is also associated with 
poor prognosis. Studies have shown that immunological damage rather than myocarditis is the predominant mechanism responsible for myocardial injury and medicines to stop the cytokine storm could lead to more rapid recovery of cardiac function [69].

Due to lack of data, there is no clear idea regarding long-term sequelae of COVID-19 on the cardiovascular system during the post-COVID era. However, it may be recommended that patients with any structural or functional abnormalities in heart should undergo a repeat echocardiogram in a span of 1-3 months after discharge and then followed up for a minimum period of 6 months. If left ventricular functional recovery is delayed beyond 3 months, more targeted heart failure therapy is advised for a minimum of 6 months to a year. Patients with persistent LV dysfunction, conduction abnormalities, or with evidence of myocardial scar must be provided long-term heart failure therapy under stringent medical attention [68].

\section{Conclusion}

Asymptomatic individuals infected with SARS-CoV-2 show mild to almost negligible symptoms, and hence, they mostly remain untested. However, hijacking the ACE2 receptor and its subsequent modulation is central to SARS-CoV-2 infection. It has been discussed in detail how ACE2 is indispensable for cardiovascular homeostasis and functioning. Hence, there is always a possibility that an individual infected by SARS-CoV-2 will develop cardiovascular complications which might even aggravate further during follow-up, even in the absence of primary symptoms of COVID-19. This is supported by the clinical studies conducted on human subjects in case of both SARS-CoV and SARS-CoV-2. Based on these findings, this article predicts a steep rise in cases of cardiovascular disorders among this undetected population harbouring the virus. Hence, it is essential that clinicians and researchers develop more efficient therapeutic management that would not only include more stringent screening for COVID-19 in the population but also look into markers of cardiovascular diseases in South Asian countries. Otherwise, we might observe a new cardiovascular pandemic in the post-COVID era in these countries, which the weak healthcare system might not be able to handle.

\section{Compliance with ethical standards}

Conflict of interest The authors declare that they have no conflict of interest.

\section{References}

1. Islam A, Ahmed A, Naqvi IH, Parveen S (2020) Emergence of deadly severe acute respiratory syndrome coronavirus-2 during 2019-2020, VirusDisease 1-9

2. Huang C, Wang YX et al (2020) Clinical features of patients infected with 2019 novel coronavirus in Wuhan, China. The lancet 395:497-506

3. Aghagoli G, Gallo Marin B, Soliman LB, Sellke FW (2020) Cardiac involvement in COVID-19 patients: Risk factors, predictors, and complications: a review. J Card Surg. https://doi. org/10.1111/jocs. 14538

4. Wang C, Xie J, Zhao L et al (2020) Alveolar macrophage dysfunction and cytokine storm in the pathogenesis of two severe COVID-19 patients. EBioMedicine 57:102833

5. Amirfakhryan H, Fatameh S (2020) Outbreak of SARS-CoV2: pathogenesis of infection and cardiovascular involvement. Hell J Cardiology. https://doi.org/10.1016/j.hjc.2020.05.007

6. Wu Z, McGoogan JM (2020) Characteristics of and important lessons from the coronavirus disease 2019 (COVID-19) outbreak in China: summary of a report of 72314 cases from the Chinese Center for Disease Control and Prevention. JAMA 323:1239-1242

7. Yamauchi-Takihara K (2011) What we learned from pandemic H1N1 influenza A. Cardiovasc Res 89:483-484

8. Li B, Yang J, Zhao F et al (2020) Prevalence and impact of cardiovascular metabolic diseases on COVID-19 in China. Clin Res Cardiol 109:531-538

9. Fung G, Luo H, Qiu Y, Yang D, McManus B (2016) Myocarditis. Circ Res 118:496-514

10. Vaduganathan M, Vardeny O, Michel T, McMurray JJV, Pfeffer MA, Solomon SD (2020) Renin-angiotensin-aldosterone system inhibitors in patients with Covid-19. N Engl J Med 382:1653-1659

11. Kassiri Z, Zhong J, Guo D et al (2009) Loss of angiotensinconverting enzyme 2 accelerates maladaptive left ventricular remodeling in response to myocardial infarction. Circ Heart Fail 2:446-455

12. Mehta M, Nerurkar R (2018) Evaluation and characterization of health economics and outcomes research in SAARC nations. Ther Innov Regul Sci 52:348-353

13. Worldometer (2020) COVID-19 Coronavirus Pandemic. Delaware, U.S.A. Available from: https://www.worldometers.info/coronavirus/

14. Wang N, Shang J, Jiang S, Du L (2020) Subunit vaccines against emerging pathogenic human coronaviruses. Front microbiol $11: 298$

15. Fehr AR, Perlman S (2015) Coronaviruses: an overview of their replication and pathogenesis. Springer, Coronaviruses, pp 1-23

16. Zhao L, Jha BK, Wu A et al (2012) Antagonism of the interferoninduced OAS-RNase L pathway by murine coronavirus ns2 protein is required for virus replication and liver pathology. Cell Host Microbe 11:607-616

17. Collins AR, Knobler RL, Powell H, Buchmeier MJ (1982) Monoclonal antibodies to murine hepatitis virus-4 (strain JHM) define the viral glycoprotein responsible for attachment and cell-cell fusion. Virol 119:358-371

18. Li W, Moore MJ, Vasilieva N et al (2003) Angiotensin-converting enzyme 2 is a functional receptor for the SARS coronavirus. Nature 426:450-454

19. Belouzard S, Chu VC, Whittaker GR (2009) Activation of the SARS coronavirus spike protein via sequential proteolytic cleavage at two distinct sites. Proc Natl Acad Sci 106:5871-5876

20. Sethna P, Hofmann M, Brian D (1991) Minus-strand copies of replicating coronavirus mRNAs contain antileaders. J Virol $65: 320-325$ 
21. de Haan CAM, Rottier PJM (2005) Molecular interactions in the assembly of coronaviruses. Adv Virus Res 64:165-230

22. Ye Y, Hogue BG (2007) Role of the coronavirus E viroporin protein transmembrane domain in virus assembly. J Virol 81:3597-3607

23. Ding Y, He LI, Zhang Q et al (2004) Organ distribution of severe acute respiratory syndrome (SARS) associated coronavirus (SARS-CoV) in SARS patients: implications for pathogenesis and virus transmission pathways. J Pathol: J Pathol Soc Great Britain and Ireland 203:622-630

24. Liang W, Feng Z, Rao S et al (2020) Diarrhoea may be underestimated: a missing link in 2019 novel coronavirus. Gut 69:1141-1143

25. Portincasa P, Krawczyk M, Machill A, Lammert F, Di Ciaula A (2020) Hepatic consequences of COVID-19 infection. Lapping or biting? Eu J Intern Med 77: 18-24

26. Zhang Y, Geng X, Tan Y et al (2020) New understanding of the damage of SARS-CoV-2 infection outside the respiratory system. Biomed Pharmacother 127:110195

27. Fan C, Li K, Ding Y, Lu WL, Wang J (2020) ACE2 expression in kidney and testis may cause kidney and testis damage after 2019-nCoV infection. MedRxiv. https://doi. org/10.1101/2020.02.12.20022418[UnpublishedPreprint]

28. Wu Y, Xu X, Chen Z et al (2020) Nervous system involvement after infection with COVID-19 and other coronaviruses. Brain Behav Immun 87:18-22

29. Li YC, Bai WZ, Hashikawa T (2020) The neuroinvasive potential of SARS-CoV2 may play a role in the respiratory failure of COVID-19 patients. J Med Virol 92:552-555

30. Gheblawi M, Wang K, Viveiros A et al (2020) Angiotensinconverting enzyme 2: SARS-CoV-2 receptor and regulator of the renin-angiotensin system: celebrating the 20th anniversary of the discovery of ACE2, Circ res 126: 1456-1474

31. Jia HP, Look DC, Tan P et al (2009) Ectodomain shedding of angiotensin converting enzyme 2 in human airway epithelia. Am J Physiol Lung Cell Mol Physiol 297:L84-L96

32. Clarke NE, Turner AJ (2012) Angiotensin-converting enzyme 2: the first decade. Int J Hypertens 2012:307315

33. Li W, Zhang C, Sui J et al (2005) Receptor and viral determinants of SARS-coronavirus adaptation to human ACE2. EMBO J 24:1634-1643

34. Heurich A, Hofmann-Winkler H, Gierer S, Liepold T, Jahn O, Pöhlmann S (2014) TMPRSS2 and ADAM17 cleave ACE2 differentially and only proteolysis by TMPRSS 2 augments entry driven by the severe acute respiratory syndrome coronavirus spike protein. J Virol 88:1293-1307

35. Tipnis SR, Hooper NM, Hyde R, Karran E, Christie G, Turner AJ (2000) A human homolog of angiotensin-converting enzyme cloning and functional expression as a captopril-insensitive carboxypeptidase. J Biol Chem 275:33238-33243

36. Hamming I, Timens W, Bulthuis MLC, Lely AT, Navis GJ, van Goor H (2004) Tissue distribution of ACE2 protein, the functional receptor for SARS coronavirus. A first step in understanding SARS pathogenesis, J Pathol: J Pathol Soc Great Britain and Ireland. 203:631

37. Doobay MF, Talman LS, Obr TD, Tian X, Davisson RL, Lazartigues E (2007) Differential expression of neuronal ACE2 in transgenic mice with overexpression of the brain reninangiotensin system. American Journal of Physiology-Regulatory, Integrative and Comparative Physiology 292:R373-R381

38. Li MY, Li L, Zhang Y, Wang XS (2020) Expression of the SARSCoV-2 cell receptor gene ACE2 in a wide variety of human tissues. Infectious diseases of poverty 9:1-7

39. Ren L, Lu X, Danser AHJ (2019) Revisiting the brain reninangiotensin system-focus on novel therapies. Curr Hypertens Rep 21:28
40. Yee AH, Burns JD, Wijdicks EFM (2010) Cerebral salt wasting: pathophysiology, diagnosis, and treatment. Neurosurgery Clinics 21:339-352

41. Donoghue M, Hsieh F, Baronas E et al (2000) A novel angiotensinconverting enzyme-related carboxypeptidase (ACE2) converts angiotensin I to angiotensin 1-9. Circ Res 87:e1-e9

42. Vickers C, Hales P, Kaushik V et al (2002) Hydrolysis of biological peptides by human angiotensin-converting enzyme-related carboxypeptidase. J Biol Chem 277:14838-14843

43. Santos RAS, e Silva ACS, Maric C et al (2003) Angiotensin-(1-7) is an endogenous ligand for the $\mathrm{G}$ protein-coupled receptor Mas, Proc Nat Acad Sci 100: 8258-8263

44. Iwata M, Greenberg BH (2011) Ectodomain shedding of ACE and ACE2 as regulators of their protein functions. Curr Enzym Inhib 7:42-55

45. Xiao F, Zimpelmann J, Agaybi S, Gurley SB, Puente L, Burns KD (2014) Characterization of angiotensin-converting enzyme 2 ectodomain shedding from mouse proximal tubular cells. PLoS One 9:e85958

46. Patel VB, Clarke N, Wang Z et al (2014) Angiotensin II induced proteolytic cleavage of myocardial ACE2 is mediated by TACE/ ADAM-17: a positive feedback mechanism in the RAS. J Mol Cell Cardiol 66:167-176

47. Hoffmann M, Kleine-Weber H, Schroeder S et al (2020) SARS$\mathrm{CoV}-2$ cell entry depends on ACE2 and TMPRSS2 and is blocked by a clinically proven protease inhibitor. Cell 181:271-280

48. Inoue Y, Tanaka N, Tanaka Y et al (2007) Clathrin-dependent entry of severe acute respiratory syndrome coronavirus into target cells expressing ACE2 with the cytoplasmic tail deleted. J Virol 81:8722-8729

49. Haga S, Yamamoto N, Nakai-Murakami C et al (2008) Modulation of TNF- $\alpha$-converting enzyme by the spike protein of SARS-CoV and ACE2 induces TNF- $\alpha$ production and facilitates viral entry. Proc Natl Acad Sci 105:7809-7814

50. Glowacka I, Bertram S, Herzog P et al (2010) Differential downregulation of ACE2 by the spike proteins of severe acute respiratory syndrome coronavirus and human coronavirus NL63. J Virol 84:1198-1205

51. Kuba K, Imai Y, Rao S et al (2005) A crucial role of angiotensin converting enzyme 2 (ACE2) in SARS coronavirus-induced lung injury. Nat Med 11:875-879

52. Jiawei C, Quanlong J, Xian X et al (2020) Individual variation of the SARS-CoV-2 receptor ACE2 gene expression and regulation. Aging Cell. https://doi.org/10.1111/acel.13168

53. Fadason T, Gokuladhas S, Golovina E et al (2020) A transcription regulatory network within the ACE2 locus may promote a proviral environment for SARS-CoV-2 by modulating expression of host factors, bioRxiv. https://doi.org/10.1101/2020.04.14.042002. [Unpublished Preprint]

54. Raizada MK, Ferreira AJ (2007) ACE2: a new target for cardiovascular disease therapeutics. J Cardiovasc Pharmacol 50:112-119

55. Crackower MA, Sarao R, Oudit GY et al (2002) Angiotensinconverting enzyme 2 is an essential regulator of heart function. Nature 417:822-828

56. Gurley SB, Allred A, Le TH et al (2006) Altered blood pressure responses and normal cardiac phenotype in ACE2-null mice. J Clin Investig 116:2218-2225

57. Yamamoto K, Ohishi M, Katsuya T et al (2006) Deletion of angiotensin-converting enzyme 2 accelerates pressure overloadinduced cardiac dysfunction by increasing local angiotensin II. Hypertension 47:718-726

58. Donoghue M, Wakimoto H, Maguire CT et al (2003) Heart block, ventricular tachycardia, and sudden death in ACE2 transgenic mice with downregulated connexins. J Mol Cell Cardiol 35:1043-1053 
59. Oran DP, Topol EJ (2020) Prevalence of asymptomatic SARSCoV-2 infection: a narrative review. Ann Intern Med. https://doi. org/10.7326/M20-3012

60. Yu CM, Wong RSM, Wu EB et al (2006) Cardiovascular complications of severe acute respiratory syndrome. Postgrad Med J 82:140-144

61. Wang X, Fang J, Zhu Y et al (2020) Clinical characteristics of noncritically ill patients with novel coronavirus infection (COVID19) in a Fangcang Hospital. Clin Microbiol Infect. https://doi. org/10.1016/j.cmi.2020.03.032

62. Puntmann VO, Carerj ML, Wieters I et al (2020) Outcomes of cardiovascular magnetic resonance imaging in patients recently recovered from coronavirus disease 2019 (COVID-19). JAMA Cardiol. e203557. https://doi.org/10.1001/jamacardio.2020.3557

63. Ece İ, Koçoğlu M, Kavurt AV et al (2020) Assessment of cardiac arrhythmic risk in children with Covid-19 infection. Pediatr Cardiol. https://doi.org/10.1007/s00246-020-02474-0

64. Goyal P, Choi JJ, Pinheiro LC et al (2020) Clinical characteristics of COVID-19 in New York City. N Engl J Med 382:2372-2374

65. Grasselli G, Zangrillo A, Zanella A et al (2020) Baseline characteristics and outcomes of 1591 patients infected with SARS-CoV-2 admitted to ICUs of the Lombardy region. Italy JAMA 323:1574-1581
66. Xiong TY, Redwood S, Prendergast B et al (2020) Coronaviruses and the cardiovascular system: acute and long-term implications. Eur Heart J 41:1798-1800

67. Corrales-Medina VF, Alvarez KN, Weissfeld LA et al (2015) Association between hospitalization for pneumonia and subsequent risk of cardiovascular disease. JAMA 313:264

68. Prabhakaran D, Perel P, Roy A et al (2020) Management of cardiovascular disease patients with confirmed or suspected COVID-19 in limited resource settings. Global Heart 15:44

69. Wang D, Li S, Jiang J et al (2019) Chinese society of cardiology expert consensus statement on the diagnosis and treatment of adult fulminant myocarditis. Science China Life sciences 62:187-202

70. The UniProt Consortium (2017) UniProt: the universal protein knowledgebase. Nucleic Acids Res 45(D1):D158-D169. https:// doi.org/10.1093/nar/gkw1099

Publisher's Note Springer Nature remains neutral with regard to jurisdictional claims in published maps and institutional affiliations. 